\title{
Relatando la memoria: ser del MIR y sobrevivir en dictadura
}

\author{
Luís A. Vivero Arriagada \\ Universidad Católica de Temuco, Chile
}

\section{Relatando la memoria: ser del MIR y sobrevivir en dictadura}

Resumen: Este documento está sustentado principalmente en los relatos de Pedro Cardyn, un ex-militante del Movimiento de Izquierda Revolucionaria (MIR). A partir de ello, se analiza sus vivencias en la lucha contra la dictadura de Pinochet en Chile, y los significados que hoy tiene aquellas utopías de los años setenta y retomadas como bandera de lucha en la década del ochenta. Es una historia de sobrevivencia y lucha, articulado con un análisis hermenéutico, que permite comprender los significados que hoy tienen la lucha revolucionaria y el haber sido víctima de violación a sus derechos fundamentales.

Palabras claves: Memoria histórica. Derechos humanos. Olvido. Dictadura.

\section{Relatando a memória: pertencer ao MIR e sobreviver na ditadura}

Resumo: Este documento é sustentado principalmente nos relatos de Pedro Cardyn, un ex-militante do Movimento da Esquerda Revolucionária (MIR). Por esses realtos, analisam-se suas experiências na luta contra a ditadura de Pinochet no Chile, e os significados que atualmente têm aquelas utopias dos anos 1970 e retomadas como bandeira de luta na década de 1980. É uma história de sobrevivência e luta, articulada a uma análise hermenêutica, que permite compreender os significados que hoje têm essa luta revolucionária e o fato de ter sido vítima de violação em seus direitos fundamentais.

Palabras-chave: Memória histórica. Direitos humanos. Esquecimento. Ditadura.

\section{Recounting a Memory: Participation in MIR and Survival under the Dictatorship}

Abstract: This document is based mainly on the reports of Pedro Cardyn, a former militant of the Revolutionary Movement of the Left (MIR) in Chile. It analyzes his experiences in the struggle against the Pinochet dictatorship and the current meanings of utopias of the 1970s that were revived in the 1980s. It is a story of survival and struggle, articulated with a hermeneutic analysis, which allows understanding the meanings that the revolutionary struggle has today and the fact of having been a victim of a violation of basic rights.

Key words: Historic memory. Human rights. Forgetting. Dictatorship. 


\section{Introducción}

Este estudio se articula en torno a dos ejes de análisis. Uno de ellos, en relación a la violación a los derechos humanos, tomando el discurso del "sujeto" que vive el evento represivo desde la construcción de la memoria histórica, desde lo cual se busca describir e intentar comprender cómo es construida hoy la memoria; el otro eje, en articulación con el anterior, pretende comprender como es interpretada hoy la lucha revolucionaria, por quien fue protagonista de un proceso "revolucionario", en la década del setenta, y luego víctima de la represión durante la dictadura de Augusto Pinochet. El protagonista del relato desde el cual se sustenta el análisis es Pedro Cardyn, médico egresado a fines de la década del sesenta de la Pontificia Universidad Católica de Chile. Un sujeto que preñado de valentía, compromiso, mística y utopía, en la década del ochenta (1981 y en plena dictadura), nuevamente se atreve a ser parte de la lucha armada, con el propósito de derrotar militar y políticamente al régimen dictatorial.

Como forma de contextualizar ese pasado al que Pedro Cardyn hará referencia en su relato, vale recordar que entre los años sesenta y setenta, el contexto latinoamericano y nacional estuvo fuertemente influenciado por el impacto de la Revolución Cubana y las luchas anticoloniales en África y en Asia. En el caso particular de Chile, esto estimuló la formación de organizaciones revolucionarias como alternativas a la política de la izquierda tradicional (VITALE, 1999). La experiencia de la política chilena queda representada en la idea de una transición pacífica y por la vía electoral al socialismo, que se materializa con el triunfo electoral de la Unidad Popular, en el año 1970, y que llevó a la presidencia a Salvador Allende Gossens, a pesar de los esfuerzos de Estados Unidos por evitar que un marxista llegara a ser presidente. En la elección anterior, este apoyo fue para el candidato de la Democracia Cristiana, Eduardo Frei Montalva, que resultó vencedor en 1964. Luego, esa misma estrategia de Estados Unidos se expresó en el apoyo financiero y material a la campaña de los contendores de Allende en el año 1970, particularmente, al candidato Radomiro Tomic del mismo partido de Frei, quien resulta tercero en la contienda electoral. Pero, la política norteamericana orientada a frenar el avance comunista en América Latina se venia dando al principio de los años sesenta, lo cual se canalizó en el eufemístico macroproyecto conocido como Alianza para el Progreso.

Lo que viene, luego que la izquierda llega al poder, es una abierta campaña de sedición organizada y dirigida por Estados Unidos con la colaboración de la burguesía criolla, en la que el Diario El Mercurio es uno de los instrumentos de sedición y propaganda más importantes de la oligarquia criolla y los sectores de ultraderecha. El rol que juega este medio escrito y su propietario, Agustín Edwards Eastman, es tan importante que es reconocido como clave en el derrocamiento del Presidente Salvador Allende en 1973, tal como lo reconoce la propia CIA en la desclasificación de archivos de dicha época. El complejo escenario histórico político de los años sesenta y setenta es, también, consecuencia de la bipolaridad generada por la "Guerra Fria".

A pesar de la dolorosa derrota de la utopía revolucionaria de la izquierda chilena y del movimiento popular (SALAZAR, 1990), que llevó a muchos a militar en las estructuras partidarias en los años sesenta y setenta, las utopías, aún hoy, permanecen allí, más evidentes que ayer y con una enorme evidencia adicional acerca de la inhumanidad no sólo de los métodos militares y políticos de lo que fue la dictadura de Pinochet, sino también de las perversas consecuencias del capitalismo en todo lo que representa el mundo de la vida. De ahí que el interés de este trabajo esté orientado a conocer y comprender, a partir del discurso de un ex-militante del Movimiento de Izquierda Revolucionaria (en adelante MIR) y protagonista de la lucha armada desarrollada en la década del setenta, los significados de la violación a los derechos humanos durante la dictadura de Augusto Pinochet, comprender los significados de la lucha armada durante dicho período y la resignificación de aquello en la actualidad.

El discurso, como relato histórico, nos permite representar la realidad como fenómeno vivenciado y objetivado por el sujeto (RICOEUR, 2008; SCHUTZ, 2003). Por lo tanto, el hecho social, amén de su concepción "objetiva", ha de ser explicado y comprendido en un 
proceso dialéctico entre explicación y comprensión. Coincidimos con Schutz (2003) que los procesos desarrollados en este "mundo de vida" buscan validarse en una práctica discursiva e intersubjetiva como contraposición a la idea dogmática de objetivación de todos los fenómenos sociales. Por ello, se asume este proceso investigativo y la opción epistemológica como un compromiso ético-político, que rescata al sujeto histórico-social como el constructor de su mundo y objetivador de su experiencia.

Entrando ya en diálogo con el entrevistado, manifiesta que prefiere que le llamen Pedro, por lo que en adelante nos referiremos a él de esta manera. Pedro Cardyn, proveniente de una familia católica practicante de clase media, ingresa al MIR luego de haber tenido una incursión como ferviente simpatizante de la Democracia Cristiana y su "Revolución en Libertad" en el año 1964. Esto fue en el marco de la campaña del candidato Eduardo Frei Montalva ${ }^{1}$. Al decir de Sader (2009, p. 143), este movimiento "era la más importante expresión de la izquierda revolucionaria en Chile y agrupaba fuerzas extraordinarias de militancia, dando muestras de organización y de creatividad política; no obstante sucumbía en una lógica de ultraizquierda." Hoy Pedro se desempeña como médico en la Atención Primaria de Salud, en el Consultorio de Panguipulli² ${ }^{2}$ Región de Los Ríos, en la Provincia de Valdivia.

Los relatos se rescatan de una entrevista en profundidad, realizada en la ciudad de Valdivia, a inicios del mes de diciembre del año 2009. Otros contactos se han continuado posterior a esta fecha, lo cual entre otras cosas, permitieron su autorización para presentar este artículo, que consideramos una exigencia ética y política y que no podíamos pasar por alto. Estos relatos permiten una reconstrucción de la historia, por medio de la oralidad y la memoria como el recurso más relevante de este proceso, que se materializa en estos actos del habla y que nos invitan a ser testigos de la oposición entre dos procesos contradictorios: el recuerdo y el olvido de la violación a los derechos humanos en la dictadura de Pinochet.

\section{Recordando la utopía del MIR y a los revolucionarios de los años setenta}

Pedro tuvo la disponibilidad y generosidad de brindarnos un espacio de su tiempo en medio de un taller de planificación del "Programa de Salud Intercultural de la Región de Los Ríos", organizado por el Servicio de Salud de Valdivia, en el cual estaba participando en su calidad de médico del Consultorio de Panguipulli. Este taller se estaba realizando en el sector Isla Teja de la ciudad de Valdivia, concretamente en la Casa de Ejercicios del Obispado, un hermoso lugar a orillas del Río Calle-Calle. Cerca de las 19 horas, iniciamos la conversación con su siguiente comentario:

[...] te hice esperar demasiado, todavía no termina esta cosa, tiene para rato, pero aprovechemos para conversar y así yo también cambio un poco de aire $[\ldots]$.

Salimos de aquel espacio cerrado y nos sentamos a orillas del río donde iniciamos el diálogo. Una de las primeras cosas que preguntó fue sobre nuestra tendencia política:

¿te puedo preguntar? [...] ¿Tú te identificas con alguna corriente de pensamiento o tendencia política?

Una pregunta muy directa que sin duda nos sorprendió y a la vez nos motivó mucho más para hablar con él. Con ese tema fuimos rompiendo el hielo. Nos cuenta que antes de ser del MIR, fue muy simpatizante y participante de la Juventud Demócrata Cristiana (JDC), cuando estudiaba medicina en Santiago ${ }^{3}$, en la Pontificia Universidad Católica de Chile, allá por los años sesenta y cuatro y su participación en la campaña presidencial de Eduardo Frei Montalva. Fuimos avanzando hacia aquello que nos interesaba y le preguntamos: ¿cuál era la utopía del MIR, de qué se trataba eso de construir "la nueva sociedad" y por qué ingresaste al movimiento? Un breve silencio, como buscando algo en sus recuerdos, como tratando de sacar aquel archivo guardado que ahora necesitaba para leer, lo que significó aquella época para él.

Te cuento: Mi papá tenía valores de lealtad, mi papá es un sobreviviente de los campos de concentración nazi, y eso que era un admirador del fascismo, admiraba las juventudes hitlerianas y todo esos [...] cuando vio la guerra se dio cuenta que no era por ahí la cosa y cayó preso por esconder a alguien de la resistencia [...].Y hay una carta donde le dice a mi mamá (mi papá era médico), le dice: 'Me ofrecieron volver en el próximo avión a Bruselas, pero yo no acepté, yo me voy a quedar hasta que se vaya el último de mis enfermos. Y te pido que no lo comentes porque no quiero aparecer como héroe o mártir de ninguna cosa'.

La fuerza que representa la figura de su familia y en particular de su padre, hoy es tan potente, que es comprensible porque a fines de los años sesenta, cuando tenía un poco más de veinte años, Pedro quería tal vez demostrar que él encarnaba los mismos valores de dignidad, solidaridad, valentía y honestidad:

Y yo veo una imagen de dignidad en mi papá, yo creo que es una cosa que a mí me marcó. 
Su vida universitária comenzó a teñirse por esa necesidad de ser parte de los cambios que estaban germinando, movilizado por aquellos valores cristianos y humanistas. Relata aquel período como un proceso en el que estaban "pasando muchas cosas", en las cuales estaba participando activamente, que poco a poco lo van llevando a cuestionarse con más fuerza la realidad social, política y económica de su época, que hoy lo representa de la siguiente forma:

La utopía para mí en esos años [...] era primero que nada ser consecuente y comprometido con los que más sufren. Yo ya entré a estudiar a la Católica, me crié en un colegio católico, donde nos enseñaban muchos de esos valores y $[\ldots]$ vine a estudiar medicina a la Católica [...] ¿qué se yo? por ahí por el año '65 o '67, época de la reforma universitaria. Ahí nos tomamos la Católica y me di cuenta que todo lo que yo pensaba que estaba en la Democracia Cristiana, una 'Revolución en Libertad', era maravilloso, sin paredones, sin los tanques de Checoslovaquia [que no sé si habían ocurrido todavía].

Lo que la Democracia Cristiana y su "Revolución en Libertad" ofrecían, a su juicio, no era suficiente para poder cambiar verdaderamente la sociedad, para lograr mayor igualdad y justicia social, porque las contradicciones estaban presentes en todos los espacios de la cotidianeidad. Llega el momento en que Pedro, ve algo distinto y así lo manifiesta hoy día:

Los campesinos de Molina ${ }^{4}$ que marcharon a Santiago, entraron al salón de Honor de la Católica y nos hablaron de la vida de la gente, de los dramas y toda la cuestión social [...]. ¡ Tomémonos la Católica!, se escuchaba. Llamamos a la clase obrera, a los sindicatos, la $\mathrm{CUT}^{5}$, las otras universidades y [...] ¡Cambiemos el mundo! Sentíamos un fervor inimaginable [...] De repente llegan a la Católica unos compañeros del MIR que ya habían egresado, gente del Pedagógico ${ }^{6}$, unos marxistas así con todo el volumen, con todas las obras de Marx y Lenin completas leídas [...]. Entonces para mí la utopía era eso, la Sierra Maestra, Vietnam (estaba empezando) y sobre todo el ejemplo de Cuba, la lucha armada, la guerrilla etc. Y yo termino mis estudios en el año 1969, me voy a Futrono ${ }^{7}$ : cordillera, trabajadores madereros, comunidades mapuche, campesinos, sindicatos: ¡y ahí era empezar la revolución!

Es importante relevar como recuerdo y práctica social, que no sólo recrea el pasado, sino que además construye el presente, por cuanto "[...] la memoria tiene el poder de construir realidades sociales, así, el pasado surge con la memoria. Interpretar el pasado es construirlo y, como hay muchas formas de interpretar un mismo acontecimiento, se pueden construir múltiples memorias" (PIPER, 2005, p. 11). Se manifiesta en el presente discurso una tensión con el pasado, que creemos tiene una influencia en la construcción de una idea de futuro.

Cardyn, para revivir su pasado lo hace desde el presente y es a partir de esta construcción intersubjetiva que hace referencia a lo que vivenció hace más de treinta años.Y así, va haciendo las conexiones dialécticamente entre el pasado y el presente:

Hoy día muchos dicen que no existe la clase obrera [...] fui militante de la clase obrera y [...] durante la dictadura yo trabajé once años en la clandestinidad y la mayor parte de las veces que pude trabajar, trabajé como obrero en la construcción, fui zapatero, artesano, pintor de brocha gorda, obrero metalúrgico, tornero de fierro [...] yo vivía en las poblaciones y todo eso.

Con su experiencia de vida y su concepción política, continúa aún hoy, después de la caída de los socialismos reales, el fin de las utopías, y la resignificación del concepto de clase, considerando a la clase obrera como la que protagonizará la tranformación de la sociedad capitalista. Esto es consecuencia de la síntesis dialectica entre presente y pasado, anclado en su experiencia, como se expresa en su relato:

Yo sigo creyendo que hoy en día la clase obrera es la única que tiene la capacidad de ver la globalidad, auque actualmente ya no encuentras esas grandes concentraciones de la clase obrera, con todo esto de las sub-contrataciones, el trabajo a domicilio, la polivalencia, parece como que se terminó la clase obrera. Yo estoy convencido que es falso. Lo que ha pasado es que la burguesía logró dividir, liquidar la conciencia organizada, los partidos los militantes; los asesinó, los desapareció, los exilió, los desorganizó [...].

Así, el concepto de sociedad, construida en los años sesenta y principios del setenta, estaba marcado por la utopía de un mundo nuevo, que es pensado desde hoy y reconstruido por la memoria, a partir de una relación de conflicto y tensión entre ese sueño las vivencias de Pedro - que las cristaliza ideológicamente como praxis de la clase obrera y la ideología dominante y hegemónica que se expresa en el actual patrón de poder del capitalismo en su fase neoliberal (QUIJANO, 2005). Las décadas del sesenta y setenta, su activismo político y posteriomente su lucha contra la dictadura en la década del ochenta, son las "cicatrices" que quedaron en Pedro Cardyn. Así mira su pasado con los cristales del presente: 


\begin{abstract}
Yo me encontraba con gente de Brasil, gente de Argentina, movimientos revolucionarios por todos lados, lucha armada, gente que se iba a la montaña, sacerdotes que dejaban la sotana y se iban a las poblaciones, estudiantes que se iban a vivir a las poblaciones, a las fábricas, a las minas, a los campos del sur a ayudar a los mapuches [...], a ayudar a los mapuches en la recuperación de tierras, la Reforma Agraria [...]. Había un destino colectivo, que era continental, que era casi mundial [...], había una sensación de que el mundo cambiaba y que uno podía cambiar [...] yo estoy convencido que nosotros tuvimos la cosa en la punta de los dedos, pudimos haber cambiado el mundo [...].
\end{abstract}

¿Para qué se luchaba en aquellos años? le preguntamos. Con expresiva seguridad, su respuesta no se hace esperar:

\begin{abstract}
Para un mundo sin desigualdad, un mundo sin consumismo, un mundo sin materialismo, un mundo donde no haya unos que nadan en riqueza mientras el resto de la gente está dando vueltas, alienadas, muriendo de hambre [...] y yo veía, [silencios] yo lo soñaba, como te digo [silencio] yo veía, por ejemplo en Futrono, las condiciones de miseria, todavía estaba la miseria dura [...].
\end{abstract}

Pero esa mirada del pasado, esa concepción de sociedad justa, sin clases, sin pobreza, en donde exista mayor igualdad, no tiene sentido sino es a partir de la mirada del presente. Un presente que se caracteriza por una crisis de la política y la apariencia de una sociedad despolitizada, que responde fielmente a la concepción neoliberal instalada durante la dictadura de Pinochet, articulada con las prácticas autoritarias y el terrorismo de Estado, (GARRETÓN, 2000; MOULIAN, 1997). Hoy, ello se expresa en un tipo de "política aideológica que no contiene proyectos, que es la petrificación absoluta del presente" (MOULIAN, 1997, p. 62). De ahí que su respuesta en torno a la pregunta ¿por qué se luchaba en aquellos años?, se nutre de una argumentación reflexiva y crítica sobre el presente, lo que le permite comprender y resignificar el pasado, lo cual queda de manifiesto en su relato:

$[\ldots]$ hoy hay una miseria de destino [...] o sea para donde mires, o sea el televisor es como el dios, el dios winka ${ }^{8}$. No hay un sentido colectivo, no hay un sentido de trascendencia, hay una miseria moral hoy en día. ¡Siento un asco por esto! Yo salí exiliado en el '84, volví en el '92 y me sigo sintiendo exiliado.

Aparece un fuerte discurso de carácter ontológico, de ser una víctima de la dictadura, en donde el ser se construye hoy en el acto del habla, a partir de aquella vivencia. Pero más que victimización, su memoria está anclada fuertemente, en el sentido de Moscovici (1993), a una acción de permanente resistencia y desafío a la dictadura, considerando que "no existen relaciones de poder sin resistencia; que éstas son más reales y más eficaces cuando se forman allí mismo, donde se ejercen las relaciones de poder" (FOUCAULT, 1992, p. 181), pero sin dejar de reconocer los significados prácticos que implicaban estos actos de resistencia en aquel momento histórico, particularmente en lo que se refiere al riesgo vital, ahí sí se ejercía literalmente el poder sobre los cuerpos.

\section{Triunfo de la Unidad Popular y el golpe de Estado: sentimientos de ayer y de hoy}

Para Pedro Cardyn el triunfo de Salvador Allende y la Unidad Popular genera sentimientos encontrados. Las utopías que abrazaba en aquellos años, son miradas desde su presente y traídas a la memoria. Es a partir de esta observación desde el presente que hacemos memoria y construimos el pasado. Entonces, ¿qué es lo que recuerda Pedro de ese momento?, ¿cómo reproduce discursivamente ese intenso y efervescente momento, que para un sector de la sociedad - clases populares y obreros principalmente - parecía que la utopía se hacia realidad? Un sueño que para estos sectores sólo duró tres años, interrumpido con el golpe de Estado y con ello diecisiete años de dictadura. ¿Cómo se recuerdan hoy esos dos acontecimientos históricos, tan contradictorios entre sí, como son las contradicciones materiales de las que habla el marxismo? Así lo relata Pedro Cardyn, haciendo una reflexión comparativa entre lo que significó el triunfo de Salvador Allende y el Golpe de Estado:

Con el golpe me pasó lo mismo que cuando Allende ganó las elecciones, pero a la inversa. Nosotros decíamos aquí por la vía electoral, no pasa nada [...] el voto más fusil era la consigna. Y ganaAllende [...] y dijimos: ‘¡chuta...!' se nos viene abajo el proyecto [...] es posible ganar sin usar las armas. Y de ahí rápidamente, los compañeros dirigentes y sobre todo Miguel Enríquez ${ }^{9}$ hacen rápidamente un análisis: que en realidad esto no es la conquista del poder es solamente la intromisión dentro del Estado burgués de una facción progresista y reformista de la izquierda, pero que el Estado burgués está intacto. Solamente tenemos una posición dentro del poder ejecutivo, pero la justicia, las FFAA, la iglesia, todo sigue en manos del modelo. No era una conquista del poder, era solamente una ampliación de las libertades democráticas y frenar un poco los afanes represivos [...] y de ahí se saca rápidamente la conclusión de que se abre un periodo democrático y de masas, que permita construir una alternativa que vaya después hacia el so- 
cialismo, hacia la revolución y el socialismo. Y que tarde o temprano, pese a las ilusiones de la UP (sus ilusiones del socialismo a la chilena, con vino y empanadas, con un clavel dentro del fusil...), íbamos a terminar en violencia y la clase dominante y el imperialismo no van a permitir el cambio [...] eso a mí no me echaba al suelo la utopía, lo que pasaba era que ahora era la guerra de verdad [...].

En primer lugar, hace un implícito reconocimiento a la confusión y desorientación que genera el triunfo de Allende, en relación a los discursos y proyectos del MIR. Era impensable la alternativa de alcanzar el poder e instalar un modelo socialista, sino por medio de las armas. Tesis que con el triunfo de la Unidad Popular, parecía ser desechable y su exclamación así lo refleja: “[...] se nos viene abajo el proyecto [...] es posible ganar sin usar las armas".

En relación a ello, aún hoy releva la importancia de Miguel Enríquez, como aquel líder que es capaz de iluminar al movimiento, cuando se genera esta confusión ideológica, que con su análisis apoyado en la teoría marxista, viene a clarificar lo que a su juicio había ocurrido. Incluso le da un crédito de premonición de lo que se venía más adelante: "tarde o temprano [...], íbamos a terminar en violencia y la clase dominante junto con el imperialismo no van a permitir el cambio". Discurso que refleja una identidad por oposición, desde sus convicciones políticas, donde el conflicto se cristaliza en la propiedad y acumulación del capital, expresada en el antagonismo entre la burguesía y el proletariado. Como señala Moulian (1997, p. 161), un discurso coherente con el de la Unidad Popular, en que "su propio ser político estaba constituido y se constituía por el antagonismo con la burguesía [...]".

Con el Golpe de Estado del 11 de septiembre de 1973, se generó primero la confusión, que luego dio paso al terror, lo cual en palabras de Moulian (1997, p. 171), "tuvo una absoluta elasticidad y en él se sostenían básicamente el orden, siendo anulada la posibilidad de movilización política así como la posibilidad de cuestionar los actos del poder." El miedo hoy se materializa como la marca dejada por la dictadura, un miedo con historia como diría Lechner (2002) que se fue apropiando de la vida de toda la sociedad, pero que se hizo más patente en aquellos y aquellas que eran partidarios del gobierno de la Unidad Popular. Por ello uno de los objetivos de la represión de la dictadura era el disciplinamiento, lo cual de acuerdo con "[...] coerción disciplinaria establece en el cuerpo el vínculo de coacción entre una aptitud aumentada y una dominación acrecentada" (FOUCAULT, 1976, p. 142), y así "el orden se afirma en el terror [...] en la combinación de recursos del poder" (MOULIAN, 1997, p. 171).
Nosotros siempre tuvimos claro que el MIR no se asilaba, aunque dentro del Comité Regional tuvimos algunas conversaciones [...] que hay que irse para Argentina de ahí volver [...] y de ahí nos llegó la orden de Santiago de que el MIR no se asila. Y yo me convencí inmediatamente que eso era lo que había que hacer. Pero, por otro lado, yo me cagué del miedo [...] o sea pasar tres semanas sin dormir, porque no podías dormir, porque no podías dormir en la noche, escuchando los disparos, los patrullajes [...] en Santiago ya me sentí más a mis anchas, me fui a vivir a las poblaciones, me empecé a sumergir, cambié de identidad [...] pero cada vez que había allanamiento o subían los milicos, era un miedo incontrolable [silencio] una cosa indescriptible, que te marca para siempre [...].

El miedo se había instalado casi instantáneamente con el Golpe de Estado, pero aún así el MIR estaba resuelto a enfrentar a la dictadura y seguir organizado, dispuesto a defender el proyecto político por el cual habían trabajado. Lo que planteaba Miguel Enríquez era quedarse en Chile para "reorganizar el movimiento de masas, buscando la unidad de toda la izquierda y de todos los sectores dispuestos a combatir la dictadura gorila" (LÖWY, 2007, p. 361). Como afirma Moulian (1997, p. 170), "en septiembre existía un clima subjetivo de crispación, exasperación, conciencia extendida de situación límite." Pero la izquierda no estaba conciente de lo dantesco que podría ser el desenlace de esa situación límite, salvo el MIR, dice Cardyn:

[...] nosotros, en el MIR, sabíamos lo que venía y que había que prepararse para eso, pero no el resto de la izquierda, digamos, a los que nosotros llamábamos reformistas, el $\mathrm{PC}^{10}$, el PS ${ }^{11}$, entre ellos Allende [...]. Me acuerdo [...] yo estaba en Valdivia para el golpe y durante tres semanas nos alojábamos aquí y allá y nos mantuvimos organizados y todos los días caía gente [...] el PC el PS, estaban en la arrancadera y nosotros éramos los únicos que estábamos tratando de sobrevivir digamos, de reorganizar la resistencia.

Pero no sólo había miedo, también había incertidumbre. No estaban preparados para enfrentar la crueldad de la dictadura, así como el país entero no lo estaba.

[...] Yo me acuerdo que dudábamos, porque de hecho quedamos desconectados a nivel nacional, cada Comité Regional tratando de sobrevivir y mantenerse organizado. Nosotros teníamos incluso un plan en caso de Golpe de Estado [...]. Me acuerdo que se había estudiado la voladura de los puentes, para que los milicos no puedan cruzar de 
sur a norte, cortar la carretera, crear el poder popular. Dos días antes, se había hecho una reunión del comando comunal de Valdivia, en que se pensaba liquidar el desabastecimiento, tomar el control de la locomoción, de las actividades productivas, de la organización de la ciudad, y crear los soviets locales.

¿Por qué no se hizo?, le preguntamos a Pedro Cardyn. Y el recuerdo nostálgico de la memoria histórica es inundado por un silencio que da cuenta tal vez de una cierta frustración, de algo que pudo haber sido distinto, si los diferentes actores afines al Gobierno de Allende hubiesen actuado de manera organizada y estuvieran preparados para enfrentar la "contrarrevolución burguesa", como lo describe Moulian (1997). Así, se cristaliza lo expresa en su discurso:

[...] porque no estábamos listos todavía, de hecho estábamos en una fase de juntar materiales, explosivos, armamentos [...], era mínimo lo que teníamos. Y además, no había un movimiento de masas [...], la masa se replegó y de hecho los dirigentes de la CUT, del PC, del PS, no tenían nada previsto en caso de golpe de Estado, no prepararon a las masas y nosotros lo intentábamos, pero el peso que teníamos dentro del movimiento de masas no era comparable al del resto de la izquierda, numéricamente, digamos [...].

Si bien se generó una resistencia al golpe de Estado, en los cordones industriales y en las poblaciones, ésta no logró la organización y coordinación para una verdadera resistencia armada, sólo se actuaba de manera improvisada (MOULIAN, 1997), lo cual coincide con lo señalado por Cardyn, en cuanto a que los partidarios de la Unidad Popular, los militantes de izquierda no estaban preparados y fueron sorprendidos por la amplitud, la violencia y la rapidez de la operación desplegada por los aparatos represivos de la dictadura, lo que cristaliza en su discurso de la siguiente manera:

[...] seguíamos con la utopía. Estábamos convencidos que esta cuestión no era eterna y que, al contrario, iba a profundizar las contradicciones de clase, la pobreza, la brutalidad, el descontento; que tarde o temprano la gente iba a responder, y de hecho, en parte fue así. O sea, durante los once años que estuve en la clandestinidad yo viví en todas las poblaciones de Santiago [...] y había un trabajo, había solidaridad, compromisos [...] por ejemplo, a mí nunca me faltó donde llegar [...] yo saqué la cuenta, durante mi clandestinidad había vivido en 63 partes distintas.
Para Pedro Cardyn, el difícil periodo de la dictadura, significó una temeraria lucha y resistencia, aunque fuese de manera fragmentada y desorganizada. A pesar de esa desorganización, las prácticas de resistencias se traducían en acciones tan sencillas, pero a la vez riesgosas, como las de albergar en las casas, a quienes eran identificados como militantes de izquierda y estaban siendo perseguidos. Una persecución que tipifica, que marca y subjetiviza. Pero además, la lectura de aquel acto de resistencia se sustenta en una concepción axiológica, que da cuenta de solidaridad y humanitarismo, lo que se manifestaba en la ayuda al perseguido. Hoy, esto es doblemente valorado, ya que se lee críticamente en virtud de los ethos individualistas de esta sociedad post-moderna neoliberal. Graficada en un discurso marcado con una aparente cuota de resignación:

Hoy día pareciera que el capital ganó la batalla [...].

De esta forma y mirando teóricamente el tema, se puede plantear que teniendo como referencia nuestro pasado y la cristalización de éste en el presente, es posible elaborar una proyección como comunidad o como sociedad-país hacia adelante. Vásquez (2001, p. 163) lo grafica de la siguiente manera:

Hacer memoria significa ubicar la construcción del pasado en la superficie de las prácticas sociales. Es decir, prescindir de la concepción de la memoria como una propiedad exclusiva y privativa de cada ser humano y considerarla un nexo relacional. Dicho con otras palabras, reemplazar el estudio de lo que ocurre en la mente de las personas y focalizar la atención sobre lo que hacemos cuando recordamos. Esto supone admitir el carácter intersubjetivo de la memoria y asumir que las explicaciones que construimos sobre el pasado son producciones contextuales, múltiples versiones creadas en circunstancias comunicativas concretas, donde el diálogo, la negociación y el debate son componentes fundamentales, lo que implica considerar la memoria como acción social.

Vale reconocer, en lo planteado por Vásquez, la influencia de la fenomenología, en tanto que la memoria es comprendida como una construcción con los alter egos, donde todas las acciones y comunicaciones realizadas por los sujetos están dotadas de significados.

\section{La Dictadura: dolor y muerte contra espe- ranza y lucha}

Sobre este proceso histórico-político, García (2004) relata como se fue organizando el MIR en la Provincia de Valdivia a fines de la década del sesenta, el entu- 
siasmo de jóvenes que tenían una utopía: un nuevo hombre, una nueva sociedad. Se sostenía la idea que ningún cambio radical sería posible, por la férrea oposición del imperialismo y que la clase dominante no aceptaría por ningún motivo, renunciar a sus históricos privilegios. Por lo tanto, para tomar el poder, no se descartaba el uso de la fuerza revolucionaria organizada de carácter político-militar. Sólo de esta forma se lograría el objetivo de la construcción de una sociedad verdaderamente socialista.

García (2004, p. 63) ${ }^{12}$ se refiere a este grupo de jóvenes de la Provincia de Valdivia, como personas de mucha convicción y pasión en sus ideas y prácticas revolucionarias, señalando explícitamente que "[...] entre los compañeros que con mayor decisión acompañaron en las tareas revolucionarias a Pepe Liendo $^{13}$ se destacaron Pedro Purísimo Barría Ordóñez, El Cojo; René Roberto Acuña Reyes, El Mono y el doctor Pedro Cardyn, doctor Kaplan." Y así lo cristaliza Pedro, en su discurso:

Él [José Liendo], y ellos, porque no estaba solo, era un grupo de compañeros que encarnaron en su práctica en irse a vivir a la montaña, de irse a vivir a las comunidades, encarnaron esos cuadros digamos, esos militantes, encarnaban en su práctica que todo era posible. Con un poquito de valor, digamos, se atrevían de la noche a la mañana de tomarse un fundo, la gente se galvanizaba y toda la gente de los alrededores iba a pedir ayuda para hacer lo mismo. Entonces, en consecuencia, una fé fenomenal, un cariño por la gente, valores humanos sobre todos. Y audacia, pero una audacia aterrizada, digamos, con la gente.

Cardyn es una historia viviente, pero que se reconstruye intersubjetivamente en ésta y otras comunicaciones, en un presente caracterizado por la despolitización y el individualismo extremo (MOULIAN, 1997; GARRETÓN, 2000). Él es un sobreviviente no sólo del golpe de Estado, sino que además de la lucha guerrillera desarrollada en la zona rural de Panguipulli, más exactamente en lo que se conocía como el "complejo maderero de Neltume". Específicamente, un sobreviviente de la guerrilla organizada por el MIR en el año 1981, en plena dictadura militar, la cual no tuvo éxito por haber sido detectada antes de tiempo. Pero más allá del fracaso y de los errores cometidos, la memoria reconstruida en el presente, le asigna una importancia fundamental a los aspectos de tipo valórico y altruista de aquellos militantes que se internaron en la montaña, para enfrentar militarmente a la dictadura y a la vez para estar ahí, con los que son explotados.

La exaltación del valor de la solidaridad, del ser consecuente entre lo que se dice y lo que se hace, son elementos fuertemente articuladores del dis- curso. Pero, también, una memoria que da cuenta de sus contradicciones y conflictos, en la praxis revolucionaria de aquellos militantes. La memoria sobre lo que se hizo en la década del ochenta, no puede ser comprendida sino a partir de lo que ocurre en 1973, que marca un antes y un después. Hoy, estos eventos son el anclaje para mirar el pasado, pensar el presente y para soñar el futuro. Es decir, la resignificación de la noción de trauma, como dice Piper (2005) se ha llevado a cabo destacando la especificidad de la violencia política y de sus efectos, diferenciándola de otras problemáticas que pertenecen a otros ámbitos. A pesar que Cardyn no menciona explícitamente esto como un hecho traumático, como consecuencia de la represión y las violaciones a los derechos humanos durante la dictadura, sus relatos están fuertemente anclados en ello:

\begin{abstract}
Bueno [...] vino el golpe, me quedé unas tres semanas en Valdivia, era insoportable vivir, porque allanaban dos veces la misma población, no había donde estar, yo era bastante conocido y no había forma de moverse. Así que con un grupo de compañeros nos fuimos a Santiago donde estuve once años en la clandestinidad [...] y en el ochenta me llaman a una reunión en que me preguntan si quería incorporarme a un grupo de compañeros que está en la montaña. Así que en mayo del ' 81 me voy a la montaña, en junio nos detectan. Hasta el mes de agosto [...] ahí estuvimos varios meses metidos en la nieve, perseguidos por aviones, helicópteros, fuerzas combinadas [...] parece que aún siento el ruido de los helicópteros sobre mi cabeza [un silencio largo y una mirada al horizonte como buscando respuesta].
\end{abstract}

En este relato a diferencia de otros, muestra con mayor nitidez los significados de la represión vivida durante la dictadura y cómo el miedo, era una constante en la población, particularmente en aquellos que estaban identificados como partidarios del Gobierno de la Unidad Popular. "Era insoportable vivir", esta frase grafica con una potente fuerza lo que se sentía y lo que aún hoy sienten muchas víctimas de la dictadura. Pero a pesar de aquel miedo, en el año 1981 nuevamente se atreve a ser parte de una experiencia revolucionaria, para la cual no estaban suficientemente preparados. Sin duda, una acción sumamente temeraria.

\section{Comentarios finales: la utopía sigue viva}

A más de 35 años del golpe de Estado y a más de 20 años de haber recuperado la democracia, Pedro Cardyn sigue soñando y de manera categórica, en una sociedad que ha declarado el fin de las utopías, dice que "lo único irreal, hoy, es no tener utopía, porque en una época como 
ésta si no se tienen sueños, se está muerto", es lo que Hinkelammert (2001) denomina la sociedad de la desesperanza. El discurso manifiesta en latencia una contradicción permanente con la sociedad actual, la que se manifiesta cristalizada en prácticas individualistas, en donde sobresale una concepción del presentismo, y una invisibilización o negación del pasado.

Nos enfrentamos a una dualidad entre memoria y olvido. Una contradicción entre esta memoria histórica que se expresa en los relatos de Cardyn y el olvido que se expresa en los discursos del Chile actual. Por lo que develar la memoria histórica es, en sí mismo, una lucha política, esperando que lo que hagamos y lo que podamos proyectar en conjunto tenga algún significado y efecto en las relaciones sociales, en nuestros pueblos adormecidos por la ideología neoliberal.

La memoria histórica expresada en relatos, nos devela la experiencia traumática de la sociedad en su conjunto y de aquellos que en sus cuerpos sufrieron la violación de sus derechos fundamentales en el periodo de la dictadura. Los mismos que siguen luchando por mantenerla como algo presente, que se cristaliza en un aprendizaje doloroso, que Pedro Cardyn lo expresa claramente:

Una cosa que fui descubriendo con el curso y el dolor de esos años, con los desarraigos, con la muerte de los compañeros, amigos, hermanos [...] la destrucción de los lazos personales, comunitarios, familiares, el exilio y toda esa atrocidad, yo diría una cosa que a lo mejor no se percibía en la intelectualidad de esa época, o en los partidos, era que combatíamos la enajenación de una manera enajenada.

Aquí, a pesar que a Pedro no le gusta hablar ni de traumas ni de víctimas, las marcas están latentes en sus discursos, verbalizadas como dolor, desaparición, muerte, destrucción de los lazos personales y sociales. La memoria histórica estará marcada por una fecha, por un tiempo objetivado en el golpe de Estado del 11 de septiembre de 1973 y los diecisiete años de dictadura del general Augusto Pinochet.

Hoy en día, muchos prefieren pensar que la estabilidad y la fortaleza del neoliberalismo global sólo permite pensar en una humanización o reforma de este sistema. Otros pensarán que los horizontes revolucionarios ya no pueden ser globales. Pero al mirar a Pedro Cardyn, al leer o escuchar sus relatos, más allá de las secuelas y traumas que podrían identificarse, que puedan aparecer evidentes o latentes en sus discursos, pareciera decirnos que a pesar del profundo miedo al sinsentido, al "fin de la historia", se puede seguir soñando con un mundo mejor, más justo, más solidario, tan simple o complejo como el soñar en ser revolucionarios otra vez.

\section{Referencias}

FOUCAULT, M. Vigilar y castigar. Argentina: Editorial Siglo XXI, 1976.

. Microfísica del poder. Madrid: Ediciones La Piqueta, 1992.

GARCÍA, J. C. Crimen sin castigo. Neltume, Santiago, Tejas Verdes. Chile: Mosquito Editores, 2004.

GARRETON, M. Política y sociedad entre dos épocas. Argentina: Editorial Homo Sapiens, 2000.

HINKELAMMERT, F. El nihilismo al desnudo. Los tiempos de la globalización. Santiago, Chile: Editorial LOM, 2001.

LECHNER, N. Las sombras del mañana. La dimensión subjetiva de la política. Chile: Editorial LOM, 2002

LÖWY, M. El marxismo en América Latina. Antología desde 1909 hasta nuestros días. Chile: Editorial LOM, 2007.

MOSCOVICI, S. Psicología social. Pensamiento y vida social. Psicología social y problemas sociales. Barcelona: Paidós, 1993. (Tomo II).

MOULIAN, T. Chile actual: anatomía de un mito. Chile: Editorial LOM/Arcis, 1997.

PIPER, I. Memoria y Derechos Humanos; Prácticas de dominación o resistencia? Chile: Editorial Arcis, 2005.

QUIJANO, A. Colonialidad del poder, eurocentrismo y América latina. In: LANDER, E. (Comp.). La colonialidad del saber: eurocentrismo y ciencias sociales. Perspectivas latinoamericanas. Buenos Aires: Clacso, 2005, p. 201-246.

RICOEUR, P. Hermenéutica y acción. De la hermenéutica del texto a la hermenéutica de la acción. Argentina: Prometeo Libros, 2008.

SADER, E. El nuevo topo. Los caminos de la izquierda Latinoamericana. Argentina: Editorial Siglo XXI, 2009.

SALAZAR, G. La violencia política popular en las "Grandes Alamedas". La violencia en Chile 1947-1987 (Una perspectiva histórico popular). Chile: Editorial LOM, 1990.

SCHUTZ, A. Estudios sobre teoría social. Argentina: Amorrortu Editores, 2003.

VÁSQUEZ, F. La memoria como acción social. Argentina: Paidós, 2001. 
VITALE, L. Contribuciones a la historia del MIR (19651970). Chile: Instituto de Investigación de Movimientos Sociales "Pedro Vuskovic", 1999.

\section{Notas}

1 Frei alcanzala presidencia de Chile con un 55,7\% de lo votos, y gobierna desde 1964 hasta 1970.

2 Panguipulli ("Cerro del puma”, de la lengua nativa mapuzungún pangipüllü), es una comuna ubicada en la Provincia de Valdivia, en la Región de Los Ríos, en el sur de Chile. Posee una población de 33.273 habitantes y una superficie de $3.332 \mathrm{~km}^{2}$. Disponible en: 〈http://www. subdere.gov.cl/1510/w3-propertyvalue-24969.html $>$.

3 Se refiere a la Capital de Chile.

4 Ubicada aproximadamente a 200 kilómetros al sur de Santiago deChile.

5 CUT, en ese entonces la Central Única de Trabajadores.

6 Se refiere al Instituto Pedagógico, adscrito a la Facultad de Filosofía y Educación de la Universidad de Chile. En 1981, elD.F.L. $N^{\circ} 1$, reestructuró dramáticamente la organización de la educación superior chilena, con el propósito de optimizar la administración educativa frente a las crecientes demandas de educación, que generaban la falta de alternativas al sistema universitario tradicional y la imposibilidad del Estado de financiar un crecimiento de ese nivel. Con esto, a través del D. F. L. N No 7, de fecha 17 de febrero de 1981, la Facultad de Educación de la Universidad de Chile daría origen a la figura del instituto profesional denominado "Academia Superior de Ciencias Pedagógicas", que posteriormente recuperaría su condición universitaria al convertirse, en 1986, en la Universidad Metropolitana de Ciencias de la Educación, UMCE. Disponible en: <http://www.umce.cl/universidad/ historia3.html>.

7 Distante a unos 100 kilómetros al oriente de la ciudad de Valdivia, pertenece a la Provincia del Ranco, de la Región de los Ríos. En la actualidad cuenta con una población de 15.699 habitantes, según censo del 2002.

8 Winka es el apelativo que usan los Mapuches en su lengua, el mapuzungun omapudungun, para referirse al no mapuche. Hoy se usa de forma muy genérica, pero en realidad tiene una connotación peyorativa, ya que significa ladrón.

9 Miguel Enríquez Espinoza, es uno de los más destacado fundadores del MIR (año 1964), el cual mure el 5 de octubre de 1974, en un enfrentamiento con un combinado militar. Resiste solo por más de dos hora. Finalmente termina acribillado con más de 10 balas en su cuerpo. Para más antecedentes sobre Miguel Enríquez, ver: <http:// www.archivochile.com/Miguel Enriquez/ Doc sobre miguel/MEsobre00000.pdf>.

10 Partido Comunista

11 Partido Socialista.

12 Cabe señalar que Pedro Cardyn me clarifica que nunca fue apodado de esta forma, lo cual le resulta muy extraño. Pero sí me comenta que algunos lo conocían como "Lautaro", y de ello se siente muy orgulloso, por "la comparación con el gran y valiente Toqui mapuche”.

13 José Gregorio Liendo Vera, conocido en esta zona como el mítico "comandante pepe", quien junto a un grupo de jóvenes militantes del MIR realizaron un enorme trabajo de concientización y promoción sociocultural y política en la enorme zona agrícola, campesina y maderera de Panguipulli.

\section{Nota da Editoria}

A Revista Katálysis recebeu de Pedro Cardyn, através de documento por ele assinado, uma declaração de aprovação do conteúdo deste ensaio.

\section{Luís A. Vivero Arriagada}

luisvive@gmail.com

Universidad ARCIS Chile

Trabajador Social, Magíster en Ciencias Sociales Aplicadas

Doctorando en Procesos Sociales y Políticos de América Latina, Universidad ARCIS

Docente de la Carrera de Trabajo Social, en la Universidad Católica de Temuco

Director de Tesis: Dr. Emilio Taddei

\section{Universidad Católica de Temuco}

Manuel Montt, n. 056

Región de la Araucanía

Casilla 15-D

Temuco - Chile 